\title{
Metal economy in host-microbe interactions
}

\author{
Frédéric J. Veyrier ${ }^{1,2 *}$ and Mathieu F. Cellier ${ }^{2 *}$ \\ ${ }^{1}$ Institut Pasteur, Paris, France \\ ${ }^{2}$ Institut National de la Recherche Scientifique-Institut Armand Frappier, Laval, Canada \\ *Correspondence: frederic.veyrier@iaf.inrs.ca; mathieu.cellier@iaf.inrs.ca
}

Edited and reviewed by:

Yousef Abu Kwaik, University of Louisville School of Medicine, USA

Keywords: metal, virulence, host, pathogen, transporter, exporter, regulation

This Research Topic presents knowledge on transition metal metabolism in various infections from the dual perspective of offender and defender.

\section{HOST NUTRITIONAL IMMUNITY: DEPRIVING OR POISONING}

To date, the implication of divalent metals have been described in two different immune strategies that aim to fight microbial invaders. One consists in depriving microbes of essential divalent metals whereas the other aims at overloading invaders with toxic concentrations of metal. The contributions in this section present, in different situations, various aspects of this metal economy at the host-microbe interface.

Two papers deal with metal homeostasis as hosts interact with bacteria. Diaz-Ochoa et al. (2014) review immunological mechanisms to sequester $\mathrm{Fe}, \mathrm{Mn}$, and $\mathrm{Zn}$ in the inflamed gut and strategies of commensals and pathogens to evade mucosal defenses and obtain such nutrients. Lisher and Giedroc (2013) detail chemical and structural mechanisms to capture $\mathrm{Mn}$, an antioxidant used by pathogens to adapt to human hosts, and the impact of Fe and $\mathrm{Zn}$ on Mn bioavailability during infections.

The most coveted metal, iron is key to nutritional immunity and microbial virulence. Using amoeba as model phagocyte, Bozzaro et al. (2013) present the tug of war between a bacterial predator, sequestering intracellular iron to resist invasion, and pathogens which elude such defense mechanisms. On mammalian defense against intracellular bacteria and protozoan parasites, Silva-Gomes et al. (2013) outline divergent approaches: iron-withholding to prevent microbial replication or iron-based oxidative injury to kill invaders.

Host may also target invaders with toxic doses of $\mathrm{Cu}$ and Zn, normally kept at low concentrations. Neyrolles et al. (2013) present an opinion article on bacterial $\mathrm{Zn}$ and $\mathrm{Cu}$ poisoning in the context of Mycobacterium tuberculosis infection. Chaturvedi and Henderson (2014) summarize the specific properties of copper and its toxic effect on bacteria cells. Arguello et al. (2013) review how bacteria integrate homeostatic mechanisms to avoid $\mathrm{Cu}$ toxicity by sensing and regulating ion chelation, chaperoning and membrane transport.

\section{MICROBIAL ADAPTATION TO HOST DEFENSES: METALLO-TRANSPORTERS OR EXPORTERS}

To overcome host resistance to infection, numerous mechanisms have been selected through the course of microbial evolution, in particular transporters that can feed the bacteria even at low metal concentration or, on the contrary, metallo-exporters that can expel metals outside the cell to avoid toxic accumulation. The articles in this section describe the microbial transport arsenal, and its regulation, which play major roles to influence metal economy at the host-microbe interface.

Bacterial and fungal strategies to acquire $\mathrm{Fe}$ is the subject of four contributions. Liu and Biville (2013) discuss erythrocyte parasitism by Bartonella, transmitted by arthropod vectors and relying principally on heme capture and oxidative stress defense to cause persistent infections. Runyen-Janecky (2013) highlights some of the recent findings on heme iron acquisition system and the regulation of their expression in Gram-negative pathogens. Cornelis and Dingemans (2013) recap how Pseudomonas adapts means of iron capture to the type of infection it establishes, acute or chronic. Caza and Kronstad (2013) contrast strategies of virulent bacteria and fungi to subvert host immunity and steal iron from hemoglobin, heme, transferrin and lactoferrin or elemental iron using specialized uptake systems and siderophores.

Five papers deal with microbial homeostasis of other metals Mn, Ni, and Zn. Honsa et al. (2013) review the roles of importers and exporters of $\mathrm{Mn}, \mathrm{Fe}, \mathrm{Zn}$, and $\mathrm{Cu}$ in Streptococcus pneumoniae gene regulation and tissue-specific pathogenesis. Guilhen et al. (2013) focus on families of exporters and the role of metal efflux in the evolution of Neisseria meningitidis virulence and naso-pharyngeal colonization. De Reuse et al. (2013) present the specific nickel needs of the gastric pathogen Helicobacter pylori and the homeostasis of nickel in this bacterium. Finally, $\mathrm{Zn}$ homeostasis is the subject of two articles. Staats et al. (2013) present the role of $\mathrm{Zn}$ in bacteria-host relationship and how this metal represents a very promising target for the development of novel antimicrobial strategies. Cerasi et al. (2013) emphasize the role of $\mathrm{Zn}$ in the host-fungi relationships and the impact of $\mathrm{Zn}$ bioavailability on the expression of virulence genes.

Lastly, metallo-regulation of bacterial gene expression is discussed in relation to virulence. Porcheron et al. (2013) review the enterobacterial metallo-transporters and their regulation, discussing strain-specific differences. Troxell and Hassan (2013) review Fe-dependent regulations of transcription by the Ferric Uptake Regulator to control iron metabolism, oxidative stress defense and virulence. Finally, Troxell and Yang (2013) present the metallo-regulation in the causative agent of Lyme disease (Borrelia burgdorferi) a bacterium that does not require iron for its metabolism. 


\section{REFERENCES}

Arguello, J. M., Raimunda, D., and Padilla-Benavides, T. (2013). Mechanisms of copper homeostasis in bacteria. Front. Cell. Infect. Microbiol. 3:73. doi: 10.3389/fcimb. 2013.00073

Bozzaro, S., Buracco, S., and Peracino, B. (2013). Iron metabolism and resistance to infection by invasive bacteria in the social amoeba Dictyostelium discoideum. Front. Cell. Infect. Microbiol. 3:50. doi: 10.3389/fcimb.2013.00050

Caza, M., and Kronstad, J. W. (2013). Shared and distinct mechanisms of iron acquisition by bacterial and fungal pathogens of humans. Front. Cell. Infect. Microbiol. 3:80. doi: 10.3389/fcimb.2013.00080

Cerasi, M., Ammendola, S., and Battistoni, A. (2013). Competition for zinc binding in the host-pathogen interaction. Front. Cell. Infect. Microbiol. 3:108. doi: 10.3389/fcimb.2013.00108.

Chaturvedi, K. S., and Henderson, J. P. (2014). Pathogenic adaptations to host-derived antibacterial copper. Front. Cell. Infect. Microbiol. 4:3. doi: 10.3389/fcimb.2014.00003

Cornelis, P., and Dingemans, J. (2013). Pseudomonas aeruginosa adapts its iron uptake strategies in function of the type of infections. Front. Cell. Infect. Microbiol. 3:75. doi: 10.3389/fcimb.2013.00075

De Reuse, H., Vinella, D., and Cavazza, C. (2013). Common themes and unique proteins for the uptake and trafficking of nickel, a metal essential for the virulence of Helicobacter pylori. Front. Cell. Infect. Microbiol. 3:94. doi: 10.3389/fcimb.2013.00094

Diaz-Ochoa, V. E., Jellbauer, S., Klaus, S., and Raffatellu, M. (2014). Transition metal ions at the crossroads of mucosal immunity and microbial pathogenesis. Front. Cell. Infect. Microbiol. 4:2. doi: 10.3389/fcimb.2014.00002

Guilhen, C., Taha, M. K., and Veyrier, F. J. (2013). Role of transition metal exporters in virulence: the example of Neisseria meningitidis. Front. Cell. Infect. Microbiol. 3:102. doi: 10.3389/fcimb.2013.00102

Honsa, E. S., Johnson, M. D., and Rosch, J. W. (2013). The roles of transition metals in the physiology and pathogenesis of Streptococcus pneumoniae. Front. Cell. Infect. Microbiol. 3:92. doi: 10.3389/fcimb.2013.00092

Lisher, J. P., and Giedroc, D. P. (2013). Manganese acquisition and homeostasis at the host-pathogen interface. Front. Cell. Infect. Microbiol. 3:91. doi: $10.3389 /$ fcimb. 2013.00091

Liu, M., and Biville, F. (2013). Managing iron supply during the infection cycle of a flea borne pathogen, Bartonella henselae. Front. Cell. Infect. Microbiol. 3:60. doi: 10.3389/fcimb.2013.00060

Neyrolles, O., Mintz, E., and Catty, P. (2013). Zinc and copper toxicity in host defense against pathogens: Mycobacterium tuberculosis as a model example of an emerging paradigm. Front. Cell. Infect. Microbiol. 3:89. doi: 10.3389/fcimb.2013.00089

Porcheron, G., Garenaux, A., Proulx, J., Sabri, M., and Dozois, C. M. (2013). Iron, copper, zinc, and manganese transport and regulation in pathogenic Enterobacteria: correlations between strains, site of infection and the relative importance of the different metal transport systems for virulence. Front. Cell. Infect. Microbiol. 3:90. doi: 10.3389/fcimb.2013. 00090

Runyen-Janecky, L. J. (2013). Role and regulation of heme iron acquisition in gram-negative pathogens. Front. Cell. Infect. Microbiol. 3:55. doi: 10.3389/fcimb.2013.00055

Silva-Gomes, S., Vale-Costa, S., Appelberg, R., and Gomes, M. S. (2013). Iron in intracellular infection: to provide or to deprive? Front. Cell. Infect. Microbiol. 3:96. doi: 10.3389/fcimb.2013.00096.

Staats, C. C., Kmetzsch, L., Schrank, A., and Vainstein, M. H. (2013). Fungal zinc metabolism and its connections to virulence. Front. Cell. Infect. Microbiol. 3:65. doi: $10.3389 /$ fcimb. 2013.00065

Troxell, B., and Hassan, H. M. (2013). Transcriptional regulation by Ferric Uptake Regulator (Fur) in pathogenic bacteria. Front. Cell. Infect. Microbiol. 3:59. doi: 10.3389/fcimb.2013.00059

Troxell, B., and Yang, X. F. (2013). Metal-dependent gene regulation in the causative agent of Lyme disease. Front. Cell. Infect. Microbiol. 3:79. doi: 10.3389/fcimb.2013.00079

Conflict of Interest Statement: The authors declare that the research was conducted in the absence of any commercial or financial relationships that could be construed as a potential conflict of interest.

Received: 15 December 2014; accepted: 19 December 2014; published online: 13 January 2015.

Citation: Veyrier FJ and Cellier MF (2015) Metal economy in host-microbe interactions. Front. Cell. Infect. Microbiol. 4:190. doi: 10.3389/fcimb.2014.00190

This article was submitted to the journal Frontiers in Cellular and Infection Microbiology.

Copyright (C) 2015 Veyrier and Cellier. This is an open-access article distributed under the terms of the Creative Commons Attribution License (CC BY). The use, distribution or reproduction in other forums is permitted, provided the original author(s) or licensor are credited and that the original publication in this journal is cited, in accordance with accepted academic practice. No use, distribution or reproduction is permitted which does not comply with these terms. 